Frankfurter elektronische Rundschau zur Altertumskunde 14 (2011)

\title{
Archäologische und naturwissenschaftliche Untersuchungen zu spätantiken Gräbern in und bei den römischen Thermen von Grumentum
}

\author{
Anemone Zschätzsch - Hans-Dieter Flad - Stephanie Ritz-Timme - Nicole von \\ Wurmb-Schwark - Hansjörg Thaler*
}

\section{Die römische Stadt Grumentum}

Die römische Stadt Grumentum liegt in Süditalien, im Innern von Lucanien, der heutigen Region Basilicata, etwa gleich weit vom ionischen und tyrrhenischen Meer entfernt, inmitten einer wunderschönen Landschaft, die zum einen durch das Agri-Tal und zum anderen durch hohe Berge gekennzeichnet ist.

Diese Stadt war in der Antike ein bedeutendes Zentrum des Binnenlandes, da sie an einem wichtigen Straßenknotenpunkt lag. Von seinem wechselhaften Schicksal in der Geschichte berichten zahlreiche Schriftsteller, wie Livius ${ }^{1}$ von den punischen Kriegen - Hannibal stand auch hier vor den Toren - oder Appian ${ }^{2}$ von den Bürgerkriegen zu Beginn des ersten vorchristlichen Jahrhunderts.

Außerhalb des Stadtgebietes sind vier monumentale Grabbauten, zahlreiche Grabinschriften und ein Aquaedukt gefunden worden. Von der Stadtbefestigung sind die Reste der Mauern unter üppigem Bewuchs noch verborgen. In der Stadt wurden bis jetzt das Forum, mehrere Tempel, ein Theater, ein Amphitheater und ein Wohnkomplex freigelegt ${ }^{3}$. Zwischen 1999 und 2003 fanden erneut Ausgrabungen statt. Ein internationales Team unter der Leitung von Hansjörg Thaler ${ }^{4}$ konnte Teile der Straßen, einen weiteren Wohnkomplex und eine Thermenanlage - zunächst durch Prospektionen, dann in mehreren Grabungskampagnen - untersuchen ${ }^{5}$.

Die Therme in Grumentum (Abb. 1) gehört nach der Typeneinteilung von D. Krencker ${ }^{6}$ zum Reihentypus, d. h. man konnte vom Eingang durch die kalten Räume über die mäßig beheizten zu den Warmbaderäumen gehen und wieder zurück. Der Baukomplex besteht aus 18 Räumen und liegt an einer Straßenkreuzung. Die Südseite grenzt an eine Hauptstraße, einen Decumanus inferior, die Ostseite an eine Nebenstraße, einen Cardo. Der gesamte Bau ist in opus reticulatum bzw. quasi reticulatum und in Ziegeltechnik errichtet. Die Mauern sind bis zu einer Höhe von 3-5 m erhalten.

Über den Eingangskorridor (R 50) gelangte man vom Decumanus inferior aus entweder in die Latrine (R 46) oder in das Frigidarium (R 48), das an zwei Seiten ein Kaltwasserbecken (R 44. 49) besaß. Von diesem zentralen Raum der Therme erreichte man einerseits den Warmbadetrakt mit einem Umkleideraum, dem Apodyterium ( $R$ 10), zwei Tepidarien (R 5. 6) und schließlich dem Caldarium (R 4) mit seinen beiden

\footnotetext{
* Dem Leiter der Ausgrabung H. Thaler wird für die Erlaubnis zur Publikation gedankt. Verantwortlich für den naturwissenschaftlichen Teil des Textes sind H.-D. Flad, S. Ritz-Timme und N. von WurmbSchwark, für den archäologischen Teil A. Zschätzsch.

${ }^{1}$ Liv. XXXIII 37,10-11. XXXVII 41-42.

${ }^{2}$ App. b. civ. I 41.

${ }^{3}$ Übersicht und Literatur bei P. Bottini (Hrsg.), Il Museo Archeologico Nazionale dell'Alta Val d'Agri (1997).

${ }^{4}$ In Zusammenarbeit mit der Soprintendenza in Potenza unter der Leitung von Maria Luisa Nava und dem Direktor des Museo Archeologico Nazionale dell'Alta Val d'Agri in Grumentum, Antonio Capano.

${ }^{5}$ H. Thaler - A. Zschätzsch, Vorbericht über die Grabungen in Grumentum, Arch. Anz. 2004/1, 241262.

${ }^{6}$ D. Krencker, Die Trierer Kaiserthermen (1929) 177 ff.
} 
symmetrisch angeordneten Warmwasserbecken. Andererseits konnte man vom Frigidarium aus in die große Halle ( $\mathrm{R}$ 45) gehen und in zwei weitere Räume (R 37. 43), deren Funktion noch nicht bekannt ist. Neben der Latrine befindet sich ein großer Raum (R 51) für die Heizanlagen.

Die Funde von vier fragmentierten Statuen, Marmorschwellen und -verkleidungen sowie die zum Teil recht gut erhaltenen schwarz-weißen Mosaikfußböden zeugen von der einst reichen Ausstattung des Gebäudes. Aufgrund der Bautechnik und der Funde kann der Bau der Therme an das Ende des 1. Jh. v. Chr. datiert werden.

Die Nutzungsdauer, so läßt sich anhand der Funde schließen, reichte bis in das 4. Jh. n. Chr. Welches Ereignis dem Badebetrieb dann ein Ende setzte, läßt sich nicht mehr ermitteln. Die Stadt war jedenfalls weiterhin bewohnt. Wann genau sie verlassen wurde, ist bislang unklar. Die Nachrichten aus dem frühen Mittelalter sind spärlich. Sicher ist nur, daß die antike Stadt niemals überbaut, sondern bis heute - soweit das Gebiet nicht zum Archäologischen Park gehört - landwirtschaftlich genutzt wird. Auf einem Hügel in der Nähe entstand im Mittelalter eine neue Stadt, die Saponara hieß und 1932 in Grumento Nova umbenannt wurde.

In und an dem Thermengebäude sind insgesamt neun sehr unterschiedliche Gräber freigelegt worden ${ }^{7}$. Diese werden im folgenden hinsichtlich ihrer Lage, Anlage, Orientierung und Beigaben von archäologischer Seite, hinsichtlich der Bestimmung von Geschlecht und Lebensalter sowie der Liegezeit von naturwissenschaftlicher Seite untersucht.

\section{Katalog der Gräber}

Grab Nr. 1: (Abb. 2)

Anlage: einfache Erdbestattung, keine Grabanlage.

Belegung: 1 Skelett

Beifunde: keine

Fundsituation: Das Skelett eines Erwachsenen wurde parallel zur Mauer 3 des Wohnkomplexes gefunden und war nach Nord-Westen orientiert.

Datierung: nicht datiert

Grab Nr. 2: (Abb. 3)

Anlage: Das Doppelgrab (2,20 x 1,60 m) an der West-Seite der Therme bestand aus gemauerten Wänden, wobei die Langseiten parallel zur Thermenmauer angelegt waren. Eine Schmalseite war bereits bei der Auffindung weggebrochen. Es fanden sich weder ein Bodenbelag noch eine Abdeckung. Die Breite des östlich gelegenen Grabes verringert sich nach Süd-Osten um etwa die Hälfte.

Belegung: 1 Skelett

Beifunde: Keramikfragmente, Glasfragmente, Aschereste.

Fundsituation: Das westliche Grab war leer, das östliche war mit einem Skelett in Rechtslage mit Kopf nach Nord-Westen belegt. Schädelteile und Oberkiefer mit gut erhaltenen Zähnen lagen zusammenhängend. Auf den Schädelfragmenten fand sich ein Stein. Teile der Brustwirbelsäule, der Lendenwirbel und der Rippen waren zusammenhängend, daran anschließend, anatomisch richtig, das Kreuzbein, das Os coccygis sowie Teile der Darmbeinschaufel gelagert. Bemerkenswerterweise befanden sich Teile des Unterkiefers und einzelne Zähne in der Nähe des Beckens und der linken Hand. Wurzelknochen, Humerus, Ulna, Radius links sind gut erhalten. Rechter

\footnotetext{
${ }^{7}$ Mit tatkräftiger Hilfe von Janine und Hans-Dieter Flad sowie Dorothea Fischer-Leonhardt.
} 
Humerus, Ulna, Radius sind teilweise fragmentiert. In dem schmaleren Bereich des Grabes lagen das rechte Bein mit Fermurteilen, Tibia, Fibula und Fußwurzelknochen. Das rechte Bein fehlt.

Datierung: nicht datiert

Grab Nr. 3: (Abb. 4)

Anlage: einfache Erdbestattung, keine Grabanlage

Belegung: 2 Skelette (Frau, Kind)

Beifunde: keine

Fundsituation: Im Tepidarium der Therme ( $\mathrm{R}$ 6) wurden parallel zur nördlichen Mauer zwei Skelette gefunden, die Köpfe zeigten nach Westen.

Das Skelett des Kindes ist vollständig vorhanden. Die Knochensubstanz ist gut erhalten, es finden sich keine Zeichen einer Knochenatrophie und keine Spuren von Gewalteinwirkung. Gut zu erkennen sind die noch nicht geschlossenen Epiphysenfugen als Zeichen des noch nicht abgeschlossenen Knochenwachstums. Die Zähne gehören zum Teil noch zu dem Milchgebiß, so daß das Alter auf unter 10 Jahre geschätzt werden kann. Die Länge des Oberarmknochens (Humerus) beträgt $15,5 \mathrm{~cm}$ und wurde in die entsprechende Regressionsgleichung zur Altersbestimmung ${ }^{8}$ eingesetzt. Dadurch läßt sich das Lebensalter des Kindes auf 5-6 Jahre eingrenzen.

Die Länge des Oberschenkelknochens (Femur) beträgt 17,2 cm, der Durchmesser der Augenhöhle (Orbita) ca. 2,8 cm.

Unter dem Skelett des Kindes lag das Skelett eines Erwachsenen. Dieses ist beschädigt und nicht vollständig. Ein langer Röhrenknochen ist überzählig und nicht sicher zuzuordnen. Soweit aus dem Fragment des Beckenknochens beurteilbar, handelt es sich um eine weibliche Person jüngeren Alters. Es finden sich keine Zeichen einer Knochenatrophie, auch keine Zeichen von Ernährungsstörungen. Das vollständige Gebiß macht einen gesunden Eindruck. Die Länge des Femurs beträgt $31 \mathrm{~cm}$, der Durchmesser der Orbita beträgt etwa $3,8 \mathrm{~cm}$.

Datierung: ca. 683-776 n. Chr. (Frau), ca. 773-887 n. Chr. (Mädchen)

Grab Nr. 4: (Abb. 5)

Anlage: Die Grabanlage $(60 \times 40 \mathrm{~cm})$ bestand aus großen abgerundeten Steinen, die zu einem Rechteck gelegt und zum Teil mit Ziegeln abgedeckt waren. Die südliche Längsseite verlief parallel und ganz dicht an Mauer 120b entlang.

Belegung: 1 Skelett eines Kindes

Beifunde: keine

Fundsituation: Das Skelett eines Kindes mißt ca. $50 \mathrm{~cm}$; es lag lang ausgestreckt, der Kopf wies nach Süd-Westen. Die Knochen lagen geordnet und sind fast vollständig vorhanden, lediglich die Fußknochen fehlen. Der Schädel, mit einem Loch über dem linken Ohr, brach beim Herausnehmen auseinander.

Datierung: ca. 663-773 n. Chr.

Grab Nr. 5: (Abb. 6)

Anlage: einfache Erdbestattung ohne Grabanlage (ca. 1,80 x 0,40 m)

Belegung: 1 Skelett

Beifunde: wenige kleine Keramikfragmente, einige Mosaiksteine, ein kleines nicht bestimmbares Bronzeobjekt (T02-233) neben den Halswirbeln.

\footnotetext{
${ }^{8}$ M. Stloukal - H. Hanakova, Die Länge der Längsknochen altslavischer Bevölkerungen unter besonderer Berücksichtigung von Wachstumsfragen, Homo 29, 1978, 53-69.
} 
Fundsituation: Das Skelett in Rückenlage ist südlich der Therme, nahe der Mauer 137, gefunden worden, der Kopf zeigte nach Süd-Westen. Die Knochen sind vollständig vorhanden, der Schädel ist zerbrochen. Wurzeln zwischen Schultern und Hals sowie am rechten Beckenknochen haben die Lage einzelner Knochen leicht verschoben. Die Arme lagen neben dem Körper, die Unterschenkel waren übereinandergelegt. Femur: $44,5 \mathrm{~cm}$.

Datierung: nicht datiert

Grab Nr. 6: (Abb. 7)

Anlage: Eine rechteckige Grabanlage mit gemauerten Seitenwänden und Bodenplatten aus Tonziegeln, eine Abdeckung hat sich nicht erhalten.

Belegung: 2 Skelette (Mann und Frau)

Beifunde:

1 Vase (T03-562), 13,5 cm hoch aus Ton (Abb. 8).

1 frg. Münze (T03-565) in einem sehr schlechten Zustand, so daß eine Bestimmung nicht möglich ist.

2 Bronzeringe (T03-563.564) mit einem Durchmesser von 2 und 0,5 cm. Es handelt sich dabei um schlichte Fingerringe ohne Verzierung.

1 frg. Bronzeblättchen (T03-561) mit einem Loch, dessen Bestimmung unsicher ist.

1 Eisennagel (T03-450).

Fundsituation: Die erste Schicht nach dem Abtragen des Humus bestand aus feiner dunkler Erde, versetzt mit einigen größeren Flußkieseln und Bruchstücken von Tonziegeln. In der Nord-Ost-Ecke ragten bereits zu diesem Zeitpunkt ein Schädel und ein Knochen heraus (Abb. 7).

In den darauffolgenden Schichten, also etwa $38 \mathrm{~cm}$ unter dem modernen Begehungshorizont, lagen dann die stark durcheinandergewirbelten (Erdbeben?) übrigen Knochen in der Nordhälfte des Grabes. Lediglich die Wirbelsäulen und ein Teil der Wirbel konnten zugeordnet werden. Es handelt sich um die Skelette zweier Personen, eines Mannes und einer Frau. In der östlichen Hälfte befand sich das männliche Skelett und in der westlichen Hälfte etwas tiefer das weibliche Skelett. Die Schädelkalotte des männlichen Skelettes ist entlang der Suturen im hinteren Teil fragmentiert, der Durchmesser der Orbita ist nicht bestimmbar. Die Länge des Femur beträgt $41 \mathrm{~cm}$, des Oberarmknochens (Humerus) $31 \mathrm{~cm}$. Vom weiblichen Skelett ist der Schädel intakt. Linker Femur: $38 \mathrm{~cm}$, Humerus: $28 \mathrm{~cm}$.

Zwischen den Knochen der Wirbelsäulen wurden zwei Bronzeringe geborgen. Dicht neben dem weiblichen Schädel, in der untersten Schicht, stand die Vase.

Da die beiden Schädel in der Nordhälfte des Grabes lagen, kann vielleicht eine Orientierung der Skelette nach Norden angenommen werden.

Datierung: ca. 436-600 n. Chr.

\section{Grab Nr. 7:}

Anlage: keine Grabanlage

Belegung: ein einzelner Knochen und ein Schädel

Beifunde: keine

Fundsituation: Im praefurnium des Raumes 51 sind ohne erkennbare Grabanlage ein einzelner Knochen (Femur) und ein Schädel gefunden worden. Die Schädelkalotte ist nicht intakt, die rechte Seite fehlt.

Datierung: ca. 257-409 n. Chr. 


\section{Grab Nr. 8:}

Anlage: keine Grabanlage

Belegung: vermutlich ein Skelett

Beifunde: keine

Fundsituation: Südlich vor Mauer 134 sind ungeordnete Knochen unmittelbar unter der Humusschicht gefunden worden. Ein Femur wurde untersucht.

Datierung: ca. 719-943 n. Chr.

\section{Grab Nr. 9:}

Anlage: Die Grabanlage mißt 1,94 x 0,52 m. Die etwa $30 \mathrm{~cm}$ hohen Seitenwände waren grob gemauert, wobei die westliche Längsseite eine halbrunde Form aufwies. Der Boden bestand aus 5 großen Ziegelplatten, eine Abdeckung war nicht oder nicht mehr vorhanden.

Belegung: kein Skelett

Beifunde: keine

Fundsituation: Der Durchgang vom Eingangskorridor (R 50) zur Latrine (R 46) wurde im Zuge der Grablege zugebaut.

Datierung: nicht datiert

\section{Die Methodik}

\section{Analyse der DNA}

Proben der Knochenfunde des kindlichen und des Erwachsenen-Skeletts aus Grab Nr. 3 wurden auf humane nukleäre und mitochondriale DNA untersucht. Dabei wurde in allen experimentellen Bereichen anlehnend an die Guidelines von Bär et al. ${ }^{9}$ gearbeitet: Alle Verbrauchsmaterialien sowie die Kugelmühle wurden vor Gebrauch ultraviolett bestrahlt. Gleiches galt für die Knochenfragmente. Diese wurden zuerst äußerlich mechanisch gereinigt, in $1 \mathrm{~cm}$ breite Stücke gesägt und UV-bestrahlt. Nach Entfernen des Alkohols in einer absteigenden Äthanolreihe wurden die gereinigten Knochenstücke zur vollständigen Trocknung über Nacht im Trockenschrank bei $60{ }^{\circ} \mathrm{C}$ inkubiert und in einer Kugelmühle zermahlen. Die DNA-Extraktion wurde aus jeweils $0.5 \mathrm{~g}$ Knochenmehl mit einem Kit der Firma Invitek (Invisorb Forensic Kit) mit leichten Modifikationen durchgeführt.

Zum Nachweis von humaner nukleärer und mitochondrialer DNA wurde eine Duplex-PCR durchgeführt, mit der simultan ein 164 bp großes Fragment des Betaglobin-Gens (als Primer für nukleäre DNA) und ein 260 bp großes Amplifikat des ND1 Gen des mitochondrialen Genoms hergestellt. Die dabei eingesetzten Primer wurden Fluoreszenz-markiert (blau für mitochondriale, grün für nukleäre DNA), so dass die markierten PCR-Produkte mittels Kapillarelektrophorese und automatischer Lasergestützter Detektion in einem ABIPrism310 (Applied Biosystems) nachgewiesen werden konnten. Für die genetische Typisierung wurde ein in der forensischen Routine für Spurenanalysen oder Abstammungsuntersuchungen gängiger PCR MultiplexKit (AmpF/STRIdentifier ${ }^{\mathrm{TM}}$ Kit, mit dem 15 short tandem repeat loci) sowie der geschlechtsbestimmende Genort amelogenin gleichzeitig amplifiziert (von WurmbSchwark et al., 2003). Die Detektion erfolgte wie beschrieben.

Um bei all diesen Untersuchungen Kontaminationen weitestgehend auszuschließen, wurden zusätzlich sämtliche Chemikalien portioniert eingesetzt und bei

\footnotetext{
${ }^{9}$ W. Bär - B. Brinkmann - B. Budowle, DNA commision of the international Society of Forensic Genetics: Guidelines for mtDNA typing, International Journal of Legal Medicine 112, 2000, 193-196.
} 
jeder Extraktion der DNA eine Positivkontrolle (DNA aus frischen Knochen), sowie eine Negativkontrolle (alle Extraktionschemikalien, aber keine biologische Matrix) durchgeführt. Gleiches galt für die PCR: In jedem Lauf wurden Positivkontrollen (DNA eines Mitarbeiters) und Negativkontrollen (alle PCR Reagenzien, aber keine DNA) eingesetzt. Die PCRs wurden an verschiedenen Tagen durchgeführt. Erst Ergebnisse, welche dreimal unabhängig voneinander zu reproduzieren waren, wurden als wahr angesehen.

Datierung der Knochenproben mit der ${ }^{14} \mathrm{C}$-Radiocarbon-Methode

Die Bestimmung der ${ }^{14} \mathrm{C}-$ Konzentrationen und die Berechnung der Datierung der Proben wurden im Leibniz Labor für Altersbestimmung und Isotopenforschung der Christian-Albrechts-Universität Kiel ${ }^{10}$ durchgeführt. Sie basiert auf der Extraktion des Kohlenstoffs aus gereinigtem Kollagen aus Knochensubstanz und der Ermittlung der simultan bestimmten ${ }^{14} \mathrm{C}-,{ }^{13} \mathrm{C}$ - und ${ }^{12} \mathrm{C}$-Konzentrationen im Vergleich zu $\mathrm{CO}_{2}-\mathrm{Me}$ standards und Nulleffekt-Proben. Das ${ }^{14} \mathrm{C}$-Alter wird nach der Methode von Stuiver und Polach" berechnet. Die Berechnung in "calibrated age" erfolgt mit CALIB rev 4.3 (Datensatz 2) ${ }^{12}$.

\section{Die Ergebnisse}

Geschlechtsbestimmungen der beiden Skelette aus Grab Nr. 3

Nach einer standardmäßigen PCR mit 30 Zyklen zeigen sich in keiner Probe Signale. Erst durch die Erhöhung auf 35 Zyklen und den Einsatz unterschiedlicher DNA-Konzentrationen sind Signale zu erhalten, wobei die Kontrollen für PCR und Extraktion negativ sind. Gleiches gilt für die genetische Typisierung mit dem AmpF/STRIdentifier ${ }^{\mathrm{TM}}$ Kit. Nach mehreren Modifizierungen sind aus beiden Knochenproben eindeutig reproduzierbar x-spezifische Fragmente nachzuweisen. Sämtliche Negativkontrollen bleiben dabei negativ, so dass davon ausgegangen werden kann, dass das untersuchte Kind und der Erwachsene tatsächlich weiblichen Geschlechts sind. Zusätzlich sind einige der kürzeren Genorte (short tandem repeats) nachzuweisen, was auf eine erwartete starke Degradierung der DNA hinweist. Offensichtlich sind nur wenige Fragmente oberhalb einer Größe von 100 Basenpaaren erhalten geblieben. Aus diesem Grund ist eine verläßliche Interpretation der Genorte bezüglich einer Verwandtschaft der beiden Personen schwierig bis spekulativ.

\section{Datierung der Skelettfunde mit der 14C-Methode}

Das berechnete Alter (calibrated ages) der untersuchten Skelette sieht folgendermaßen aus:

Grab Nr. 3:

Kindliches Skelett: 773-887 n. Chr. (Wahrscheinlichkeit 92,5\%)

Erwachsenes Skelett: 683-776 n. Chr. (Wahrscheinlichkeit 95,4\%).

Grab Nr. 4:

Femur des Kindes: 663-773 n. Chr. (Wahrscheinlichkeit 95,4\%)

Grab Nr. 6:

\footnotetext{
${ }^{10}$ Institut für Rechtsmedizin im Universitätsklinikum Schleswig-Holstein, Campus Kiel, unter der Leitung von Prof. Dr. P. M. Grootes.

${ }^{11}$ M. Stuiver - H. A. Polach, Discussion: Reporting of 14C data, Radiocarbon 19, 1977, 355-363.

${ }^{12}$ M. Stuiver u. a., INTCAL98 Radiocarbon age calibration 24,000-0 cal BP, Radiocarbon 40, 1998, 1041-1083.
} 
Femur des Mannes: 436-600 n. Chr. (Wahrscheinlichkeit 95,4\%)

Grab Nr. 7:

Femur: 257-409 n. Chr. (Wahrscheinlichkeit 95,4\%)

Grab Nr. 8:

Femur: 719-943 n. Chr. (Wahrscheinlichkeit 95,4\%)

\section{Schlußbetrachtung}

\section{Anlage der Gräber}

Alle neun bei der römischen Therme gefundenen Gräber unterscheiden sich hinsichtlich ihrer Lage, Anlage und Orientierung. Es gibt Knochenfunde sowohl ohne Grabanlage innerhalb (3. 7) und außerhalb (1.5.8) der Therme als auch in Grabanlagen in unmittelbarer Nähe der Außenmauern (2. 4. 6. 9). Die Gräber sind in fast gleicher Höhe ü. NN angelegt, und die Orientierung der Toten ist, soweit sich das noch feststellen läßt, uneinheitlich.

\section{Grabbeigaben}

Die geringen Grabbeigaben (2. 5. 6) sind leider wenig aussagekräftig. Die Keramikfragmente stammen aus einheimischer Produktion, die sich über Jahrhunderte kaum verändert hat. Die Glas- und Bronzeobjekte sowie die Bronzeringe aus Grab 6 sind ohne jede Verzierung und daher nicht zu datieren. Die kleine Vase aus Grab 6 gibt zumindest den Hinweis, daß es sich um das älteste der Gräber handeln könnte. Denn der Brauch, einen Toten mit Beigaben auszustatten, wurde seit dem frühen Mittelalter eingeschränkt und Ende des 7 . Jhs. ganz eingestellt ${ }^{13}$. Diese Einschätzungen der Archäologen wurden später durch die Altersbestimmungen der naturwissenschaftlichen Untersuchung bestätigt.

\section{Datierung}

Da also die Beifunde für eine Datierung nicht weiterhelfen, sind die Ergebnisse der naturwissenschaftlichen Untersuchungen für den Archäologen von großer Bedeutung. Für die Skelette aus fünf Gräbern konnten das Geschlecht und die Liegezeiten bestimmt werden. Die älteste Datierung 257-409 n. Chr., die für den vereinzelt gefundenen Knochen aus Grab 7 ermittelt wurde, muß bei der Betrachtung außer acht bleiben. Da keine Anzeichen für eine Grabanlage vorhanden sind, können dieser und ein weiterer in der Nähe gefundener Schädel später zufällig an diesen Platz geraten sein, denn bis in das 4. Jh. existierte die römische Stadt und die Therme war sehr wahrscheinlich noch in Betrieb. Die anderen Toten sind von frühestens ca. 436 bis spätestens ca. 943 mehr oder weniger sorgfältig bestattet worden.

\section{Herkunft der Toten}

Die Frage, welcher Ethnie die Toten angehörten, läßt sich weder von der naturwissenschaftlichen noch von der archäologischen Seite beantworten. In Italien herrschten in diesen Jahrhunderten sehr unruhige Zeiten, was auch die Flüchtigkeit der Grabanlagen erklären könnte. In diesen Zeitraum fallen die Eroberung Italiens durch die Ostgoten (etwa 493-553), die oströmische Invasion (etwa 535-553) und die Errichtung des Langobardenreiches, insbesondere des Herzogtums Benevent (580-1047). Wer von diesen Eindringlingen aber überhaupt das obere Agrital erreicht hat, ist bisher weder den historischen noch den archäologischen Zeugnissen eindeutig zu entnehmen. Es

\footnotetext{
${ }^{13}$ H. Jedin (Hrsg.), Handbuch der Kirchengeschichte II, 1 (1973) 343.
} 
könnte sich also bei den in der Therme gefundenen Gräbern sowohl um Bestattungen der einheimischen Bevölkerung als auch um Angehörige fremder Völker handeln. Soweit es noch feststellbar ist, waren die Bestatteten zu ihren Lebzeiten gesund, es wurden keine Knochenatrophie oder sonstige Ernährungsstörungen festgestellt, und sie kamen nicht durch Gewalteinwirkungen zu Tode. Das spricht vielleicht eher für Gräber von Einwohnern der noch bestehenden Stadt Grumentum.

\section{Christliche Gräber?}

Nach der Lage der Gräber und der naturwissenschaftlichen Bestimmung der Liegezeit der Bestatteten kann man einen interessanten Anhaltspunkt gewinnen. Römische Thermen wurden im frühen Mittelalter oft - vielleicht nicht zuletzt wegen ihrer Apsiden und des verfügbaren Wassers für die Taufe - als Kirchen verwendet bzw. zu Kirchen umgebaut. Dies könnte auch für Grumentum zutreffen.

Die Lage der Gräber zeigt einerseits, daß die Therme zur Zeit der Grablegungen nicht mehr in Betrieb war und möglicherweise schon außerhalb des Wohngebietes gelegen haben muß, denn in antiker und frühchristlicher Zeit durften die Toten nicht innerhalb einer Siedlung bestattet werden.

Andererseits wird die Anlage der Gräber entlang von Mauern kaum zufällig erfolgt sein. Wenn also eine bestimmte Absicht angenommen werden kann, dann wohl ein ab dem 4. Jh. n. Chr. bereits tolerierter, im 6. Jh. legalisierter Brauch: Damals begann man, Bestattungen innerhalb oder in unmittelbarer Nähe von Kirchen, besonders aber bei Heiligen- oder Märtyrergräbern ${ }^{14}$ bzw. Kirchen mit Reliquien vorzunehmen, die dann auch im Stadtgebiet liegen konnten.

Die Errichtung einer Kirche zu Ehren eines Märtyrers ist für Grumentum durchaus denkbar. So wird in den Legenden überliefert, daß 258 n. Chr. zwölf Brüder auf ihrem Weg von Afrika nach Süditalien zum Martyrium auch Grumentum besucht hätten ${ }^{15}$ und daß 312 n. Chr. San Laviero, der auch der ,primus Lucaniae martyr“ genannt wurde, in Grumentum in der Nähe des Forums - also nach heutigen Erkenntnissen in unmittelbarer Nähe der Therme - hingerichtet worden $\mathrm{sei}^{16}$. Sehr früh gab es nach den literarischen Quellen in Grumentum eine christliche Gemeinde ${ }^{17}$.

\section{Zusammenfassung}

Für die Therme und die Gräber ergibt sich daraus folgendes: Die Therme in Grumentum könnte in der Spätantike - nach den Belegungszeiten frühestens 450-500 n. Chr. - zu einer Kirche umgebaut worden sein oder sie war zu dieser Zeit eine Ruine, die man für eine Kirche halten konnte. Die Gräber wurden entweder innerhalb oder in der Nähe dieser Kirche bzw. Ruine angelegt und enthalten deshalb mit einiger Sicherheit christliche Bestattungen.

\footnotetext{
${ }^{14}$ RAC 12 (1983) 366-397 s. v. Grab (B. Kötting).

${ }^{15}$ Acta Sanctorum, September II Kap. IV S. 134-136.

${ }^{16}$ F. Ughelli, Narratione del Martirio di S. Laviero 312, in: Italia Sacra (Roma 1659) VII, 678-689 (493) [Nachdr. 1972-85].

${ }^{17}$ s. V. Falasca, Grumentum, Saponaria, Grumento Nova. Storia di una comunità dell'Alta val D'Agri (Potenza ${ }^{2}$ 1997) 37-40.
} 

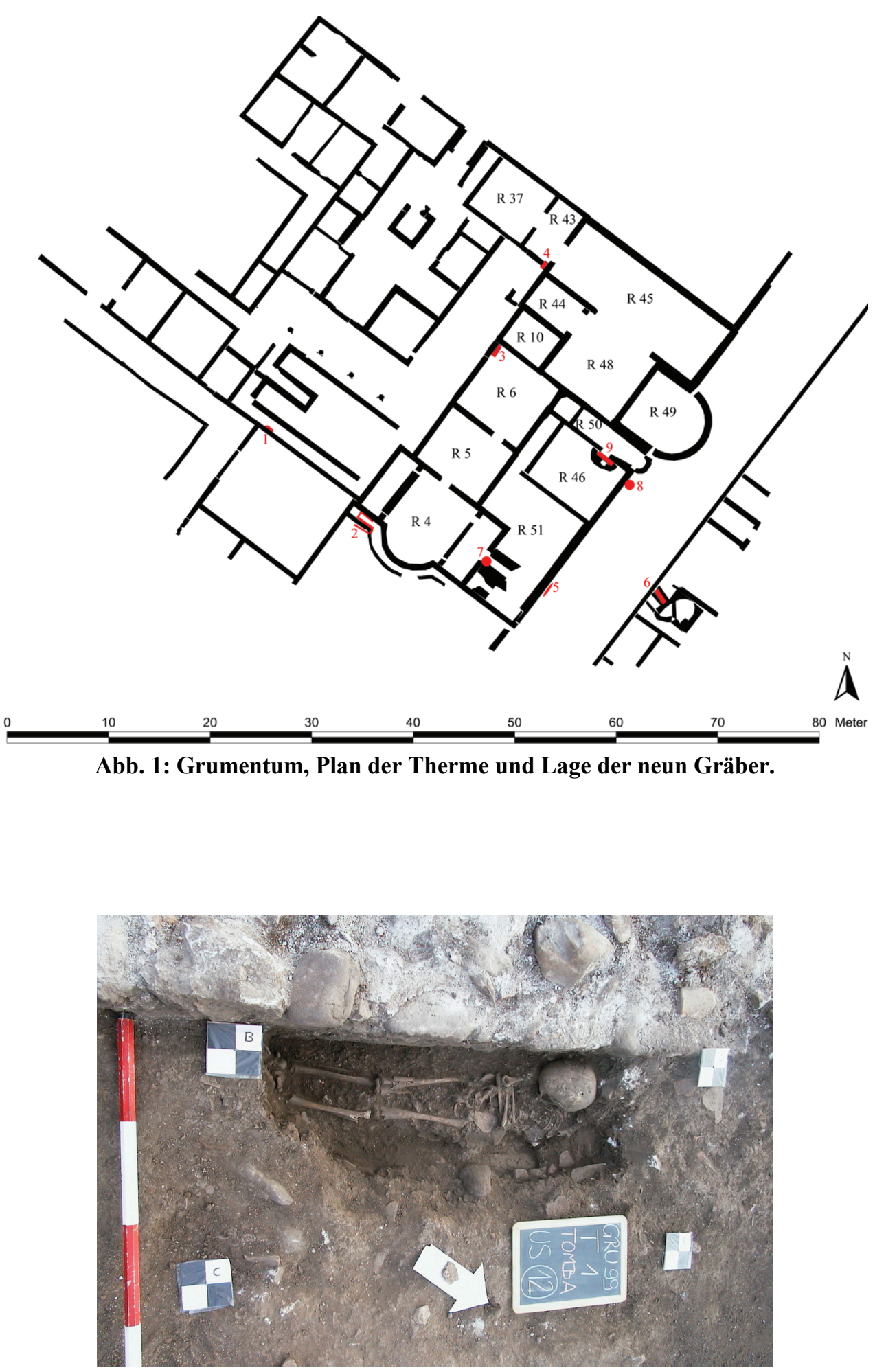

Abb. 2: Grab Nr. 1. 
Frankfurter elektronische Rundschau zur Altertumskunde 14 (2011)

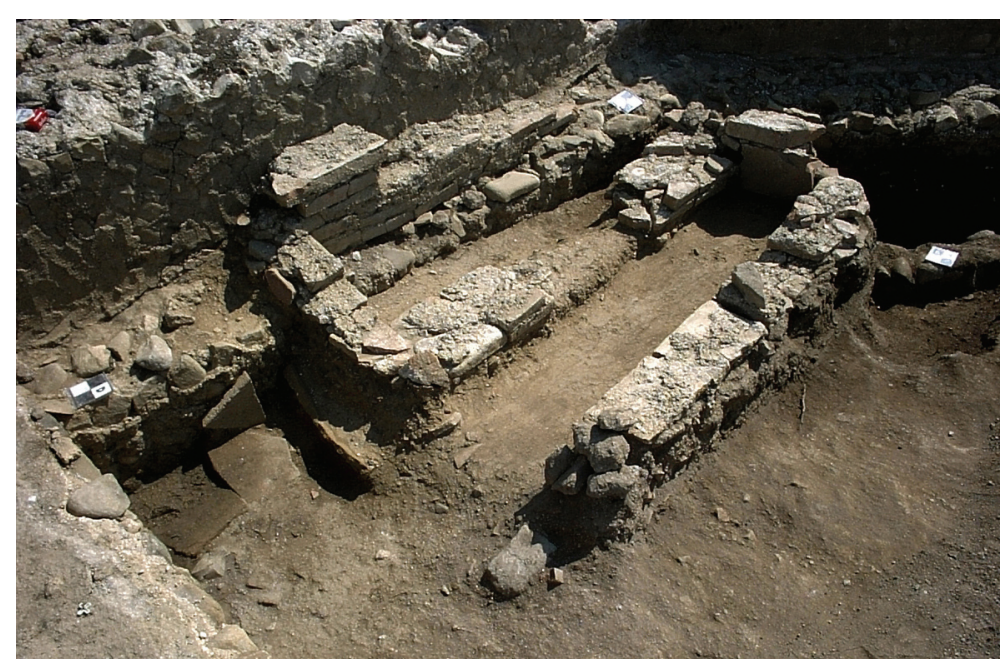

Abb. 3: Grab Nr. 2.

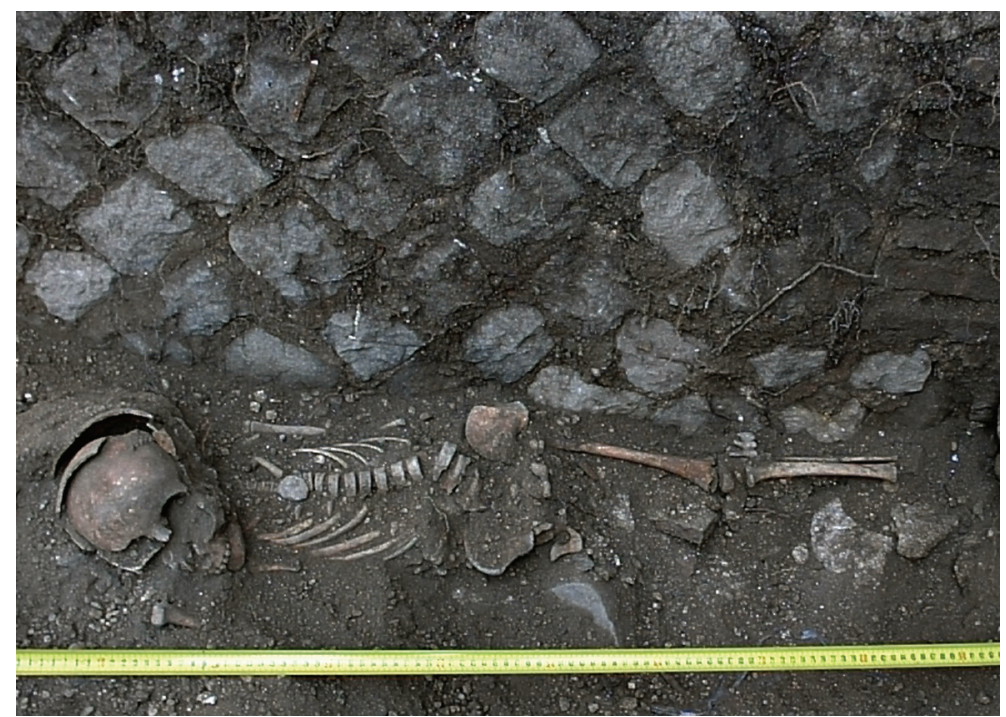

Abb. 4: Grab Nr. 3.

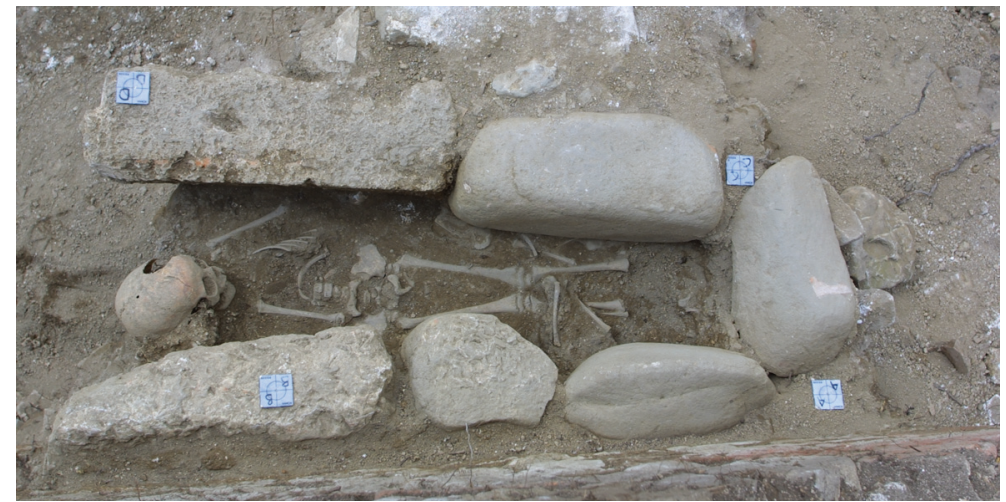

Abb. 5: Grab Nr. 4. 
Frankfurter elektronische Rundschau zur Altertumskunde 14 (2011)

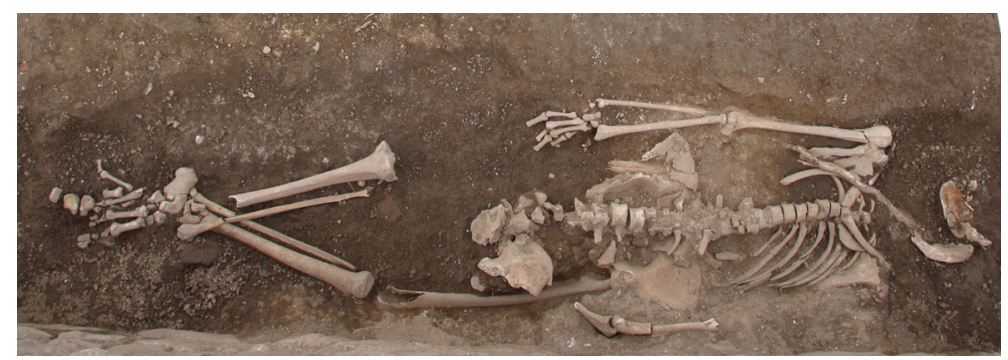

Abb. 6: Grab Nr. 5.

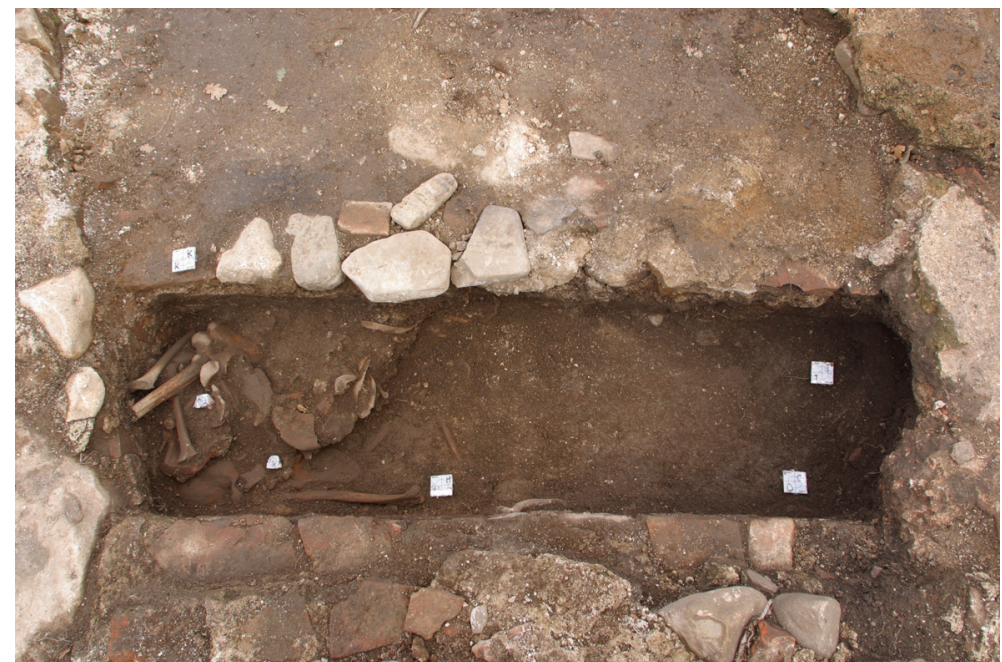

Abb. 8: Grab Nr. 6. Knochen des Mannes.

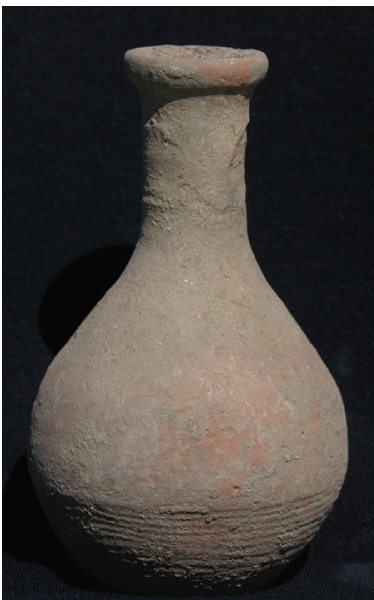

Abb. 7: Vase aus Grab Nr. 6.

\section{Adressen der Autoren:}

Prof. Dr. Hans-Dieter Flad

Forschungszentrum Borstel

Parkallee 1-40

23845 Borstel

Prof. Dr. Stefanie Ritz-Timme

Institut für Rechtsmedizin

Heinrich-Heine-Universität

Moorenstraße 5

40225 Düsseldorf

Prof. Dr. rer. nat. Nicole von Wurmb-Schwark

Institut für Rechtsmedizin

Universitätsklinikum Schleswig-Holstein Campus Kiel

Arnold-Heller-Straße 12

24105 Kiel

Dr. Anemone Zschätzsch

Institut für Klassische Archäologie

Johannes Gutenberg Universität

Saarstraße 21

55099 Mainz 